\title{
Assessment of genetic diversity in Amomum tsao-ko Crevost \& Lemarié, an important medicine food homologous crop from Southwest China using SRAP and ISSR markers
}

\author{
Mengli Ma $\cdot$ Tiantao Wang $\cdot$ Bingyue Lu $\mathbb{D}$
}

Received: 23 September 2020/Accepted: 5 May 2021/Published online: 20 May 2021

(C) The Author(s), under exclusive licence to Springer Nature B.V. 2021

\begin{abstract}
Amomum tsao-ko Crevost \& Lemarié is an important crop that has been widely used in traditional Chinese medicine and daily diets for a long time. In this study, the genetic diversity and relationships of eight cultivated populations of A. tsao-ko grown in Southwest China were examined using sequencerelated amplified polymorphism (SRAP) and intersimple sequence repeat (ISSR) markers. The results showed that $139(99.29 \%)$ of 140 and 185 (99.46\%) of 186 bands were polymorphic by SRAP and ISSR primers amplification, respectively. The polymorphic information content of detected bands were 0.270 (SRAP) and 0.232 (ISSR), respectively. The average Nei's gene diversity $(\mathrm{H}=0.217)$ and Shannon's information index $(\mathrm{I}=0.348)$ at the species level generated by SRAP primer were higher than those by ISSR analysis $(\mathrm{H}=0.158, \mathrm{I}=0.272)$. Genetic differentiation coefficients and molecular variance analysis (AMOVA) indicated that the genetic variance of $A$. tsao-ko mainly occurred within populations rather than among populations. The high genetic identity among populations was revealed by $\operatorname{SRAP}(0.937)$ and ISSR (0.963). Using UPGMA cluster analysis, principal coordinate analysis, and population structure
\end{abstract}

M. Ma $\cdot$ T. Wang $\cdot$ B. Lu ( $₫)$

Key Laboratory for Research and Utilization of Characteristic Biological Resources in Southern Yunnan, College of Biological and Agricultural Sciences, Honghe University, Mengzi, Yunnan, People's Republic of China e-mail: 1by202@126.com analysis, the accessions were categorized into two major groups. Overall, results obtained here will be useful for $A$. tsao-ko germplasm characterization, conservation, and utilization.

Keywords Amomum tsao-ko - Genetic variance . Molecular markers · Population structure

\section{Introduction}

Amomum tsao-ko Crevost \& Lemarié, commonly known as black cardamom, is a perennial evergreen tufted herb belonging to the family Zingiberaceae. It is mainly distributed in Southwest China and Northern Vietnam at altitudes ranging from 1300 to $1800 \mathrm{~m}$ and is a type of economic crop that grows in humid forests (Liu et al. 2019; Wu and Raven 2000). The dried ripe fruit of A. tsao-ko (Cao-guo in Chinese) is often used to treat internal resistance to cold and dampness, epigastric distension, fullness and vomiting, and malaria among other ailments (Lim 2013; Shi et al. 2014). In addition, A. tsao-ko is also used in the clinical treatment of patients with novel coronavirus pneumonia (COVID-19) in China, indicating that $A$. tsao-ko also plays an important role in antiviral therapy (Zong 2020). According to statistics, A. tsao-ko planting area in Yunnan Province was over 229. 300 hectares (average production about $7.5 \mathrm{t} / \mathrm{ha}$ ), 
accounting for over $95 \%$ of the cultivation area in China (Ma et al. 2020), it is one of the most important economic sources in southwest mountainous regions of China, the current market price of which is approximately $60 \sim 100 \quad$ RMB per kilogram (Yang et al. 2017).

Germplasm resources are the basic materials for fine variety breeding. Breeding effectiveness not only depends on the number of germplasm resources but also largely depends on the mastery of genetic characteristics of the diversity of these germplasm resources. In recent years, molecular marker technology has been widely used to study the genetic diversity of crop germplasm resources. Sequence-related amplified polymorphism (SRAP) is a unique double primer design to specifically amplify the intron region and promoter region of open reading frames (ORFs) $(\mathrm{Li}$ and Quiros 2001). Polymorphism occurs due to different lengths of introns, promoters, and spacers in different individuals and species. Presently, SRAP has been successfully applied to the analysis of crop genetic diversity, the construction of a genetic map, and the marking of important traits (Robarts and Wolfe 2014). Inter-simple sequence repeats (ISSRs) are an oligonucleotide primer based on simple sequence repeats (SSRs) in the genome that uses higher annealing temperature and longer primers. This leads to high repeatability and good stability and does not require prediction of genomic DNA sequence, polymorphism, and rich information (Zietkiewicz et al. 1994). ISSRs have been widely used in the study of genetic diversity of crop germplasm resources (El-tayeh et al. 2020; Zafar-Pashanezhad et al. 2019; Zhang et al. 2020).

Previous studies have focused on A. tsao-ko as a traditional Chinese medicine and condiment. Researchers have mainly conducted experiments on essential oil extraction, chemical composition analysis, and pharmacological action (Kim et al. 2019; Liu et al. 2018; Sim et al. 2019). However, few reports have highlighted the genetic diversity of A. tsao-ko. In recent years, with increasing awareness of identification and protection of crop resources, research on the genetic diversity of A. tsao-ko has increased gradually. Zhang et al. (2019) analyzed the phenotype of A. tsao$k o$ characteristics in nine producing areas of Yunnan Province in China. The results showed that the maximum straight diameter variation of fruit ridge number, single fruit seed number, and fruit vertical diameter were the largest. Yang et al. (2014) developed 24 pairs of simple repeat sequence (SSR) primers by FIASCO technique, but only nine of them were polymorphic. We also analyzed the genetic diversity of A. tsao-ko in eight populations in Yunnan Province using 12 RAPD markers, and the results showed that the genetic differentiation of $A$. tsao-ko mainly existed within the population (Lu et al. 2018). In this study, SRAP and ISSR molecular markers were used to analyze the genetic diversity of eight populations in China, evaluate the level of genetic diversity of $A$. tsao-ko, and reveal the distribution pattern of intrapopulation/inter-population genetic variation. The results are of great significance for the preservation and sustainable utilization of $A$. tsao-ko resources.

\section{Materials and methods}

Plant materials

A total of 91 accessions from eight cultivated populations of A. tsao-ko were collected from Yunnan Province, China (the main producing area). When sampling, the linear distance between the samples in the same population was not less than $50 \mathrm{~m}$. The information of the sampling sites is shown in Fig. 1 and Table 1.

\section{DNA extraction}

The genomic DNA of $A$. tsao-ko was extracted using the cetyltrimethylamine bromide (CTAB) method (Doyle and Doyle 1987), and the concentration and quality of DNA were detected by a NanoDrop 2000 ultra-micro spectrophotometer. The working solutions of genomic DNA $(20 \mathrm{ng} / \mu \mathrm{L})$ of different samples were stored at $4{ }^{\circ} \mathrm{C}$.

\section{PCR amplification}

A total of nine pairs of SRAP and eight ISSR primers with clear banding patterns and polymorphism were selected to analyze the genetic diversity of A. tsao-ko (Table 2). All amplifications were performed using an ETC-811 PCR Thermal cycler (Eastwin, Beijing, China). The $10 \mu \mathrm{L}$ SRAP-PCR reaction system consisted of $\sim 10 \mathrm{ng}$ template DNA, $1.25 \mu \mathrm{L}$ $10 \times$ PCR buffer $\left(\mathrm{Mg}^{2+}\right.$ plus $), 1 \mathrm{U}$ Taq DNA 


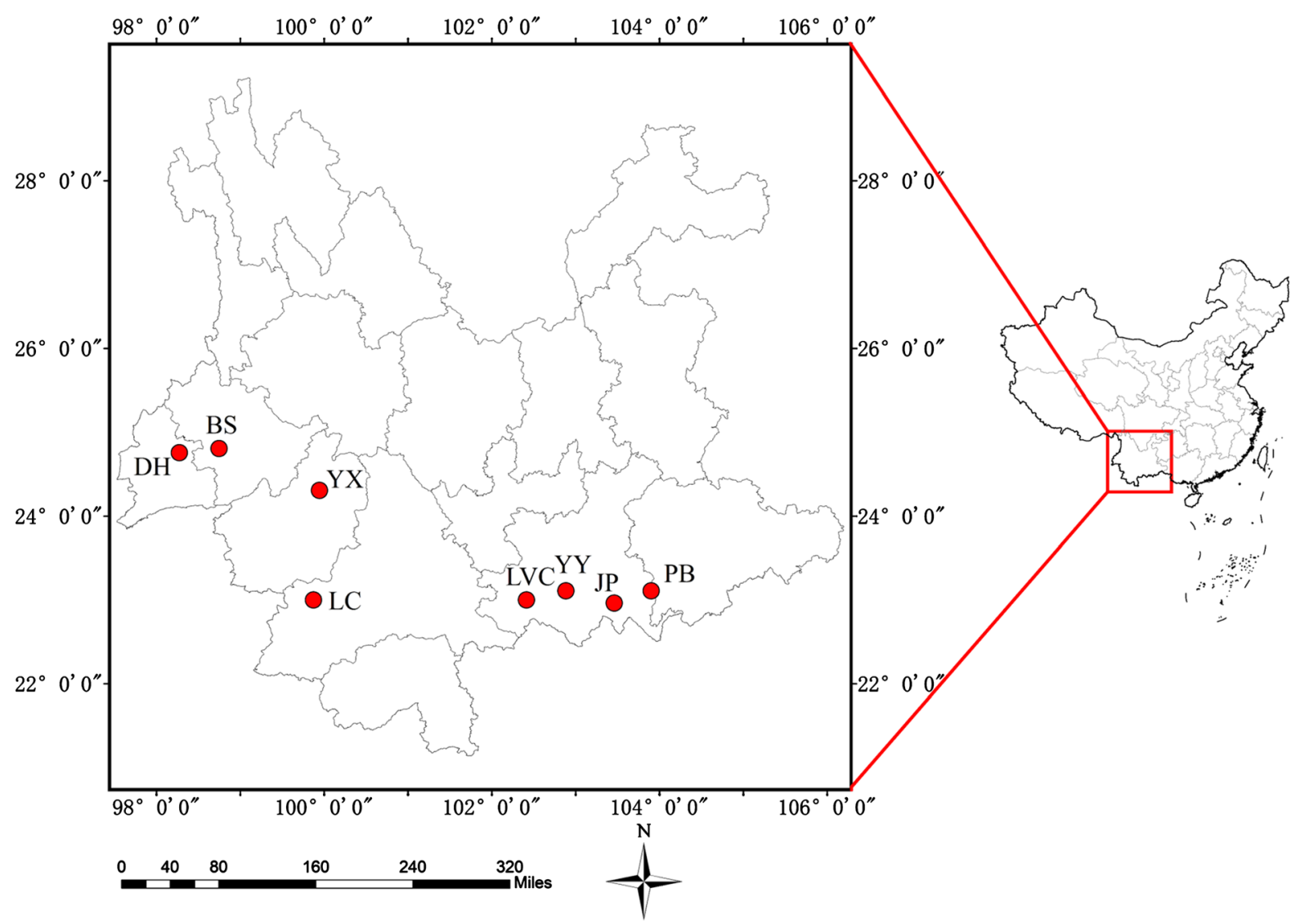

Fig. 1 Map of A. tsao-ko samples collection sites. PB, Pingbian population; JP, Jinping population; YY, Yuanyang population; LVC, Lvchun population; YX, Yunxian population; LC, Lancang population; BS, Baoshan population; DH, Dehong population

Table 1 Original information and number of A. tsao-ko samples used in this study

\begin{tabular}{llllll}
\hline Population & No. of samples & Latitude $(\mathrm{N})$ & Longitude (E) & Altitude (m) & Location \\
\hline PB & 9 & $23^{\circ} 2^{\prime} 24^{\prime \prime}$ & $103^{\circ} 31^{\prime} 48^{\prime \prime}$ & 1721 & Pingbian, Yunnan \\
JP & 13 & $22^{\circ} 54^{\prime} 36^{\prime \prime}$ & $103^{\circ} 13^{\prime} 12^{\prime \prime}$ & 1665 & Jingping, Yunnan \\
YY & 12 & $23^{\circ} 3^{\prime} 0^{\prime \prime}$ & $102^{\circ} 55^{\prime} 12^{\prime \prime}$ & 2108 & Yuanyang, Yunnan \\
LVC & 11 & $22^{\circ} 53^{\prime} 24^{\prime \prime}$ & $102^{\circ} 24^{\prime} 43^{\prime \prime}$ & 1880 & Lvchun, Yunnan \\
YX & 10 & $24^{\circ} 17^{\prime} 24^{\prime \prime}$ & $100^{\circ} 6^{\prime} 36^{\prime \prime}$ & 1811 & Yunxian, Yunnan \\
LC & 13 & $22^{\circ} 54^{\prime} 36^{\prime \prime}$ & $99^{\circ} 49^{\prime} 12^{\prime \prime}$ & 1924 & Lancang, Yunnan \\
BS & 11 & $24^{\circ} 83^{\prime} 48^{\prime \prime}$ & $98^{\circ} 77^{\prime} 81^{\prime \prime}$ & 1873 & Baoshan, Yunnan \\
DH & 12 & $24^{\circ} 75^{\prime} 0^{\prime \prime}$ & $98^{\circ} 18^{\prime} 36^{\prime \prime}$ & 1822 & Lianghe, Yunnan \\
\hline
\end{tabular}

polymerase, $0.2 \mathrm{mmol} / \mathrm{L}$ dNTPs, and $0.2 \mu \mathrm{mol} / \mathrm{L}$ each of SRAP forward and reverse primers. The PCR reaction procedure was as follows: denaturation at $95{ }^{\circ} \mathrm{C}$, annealing at $35^{\circ} \mathrm{C}$, annealing at $72{ }^{\circ} \mathrm{C}$, extension for $1 \mathrm{~min}$ at $72{ }^{\circ} \mathrm{C}(5$ cycles $)$, then increasing the annealing temperature to $50{ }^{\circ} \mathrm{C}$ to amplify 35 cycles, and a final extension at $72{ }^{\circ} \mathrm{C}$ for $7 \mathrm{~min}$ to preserve at $4{ }^{\circ} \mathrm{C}$. The optimum ISSR reaction system $(25 \mu \mathrm{L})$ included $\sim 50$ ng template DNA, $3.0 \mu \mathrm{L} 10 \times$ PCR buffer $\left(\mathrm{Mg}^{2+}\right.$ plus), 1.5 U Taq DNA polymerase, $0.25 \mathrm{mmol} / \mathrm{L} \mathrm{dNTPs}$, and $0.3 \mu \mathrm{mol} / \mathrm{L}$ ISSR primers. The PCR procedure included pre-denaturation $\left(95^{\circ} \mathrm{C} /\right.$ 5 min), followed by $95{ }^{\circ} \mathrm{C} / 1 \mathrm{~min}, 48{ }^{\circ} \mathrm{C}-54{ }^{\circ} \mathrm{C} /$ $1 \mathrm{~min}, 72^{\circ} \mathrm{C} / 1 \mathrm{~min}$, a total of 35 cycles, and finally extended at $72{ }^{\circ} \mathrm{C}$ for $10 \mathrm{~min}$ to preserve at $4{ }^{\circ} \mathrm{C}$. The amplified products were separated on $8 \%$ (SRAP) and 
Table 2 Sequences of 9 SRAP primer combinations and 8 ISSR primers

\begin{tabular}{llllll}
\hline $\begin{array}{l}\text { SRAP primer } \\
\text { combinations }\end{array}$ & Forward primer $\left(5^{\prime}-3^{\prime}\right)$ & Reverse primer $\left(5^{\prime}-3^{\prime}\right)$ & $\begin{array}{l}\text { ISSR } \\
\text { primers }\end{array}$ & $\begin{array}{l}\text { Sequences }\left(5^{\prime}-\right. \\
\left.3^{\prime}\right)\end{array}$ & $\begin{array}{l}\text { Annealing } \\
\text { temperature }\left({ }^{\circ} \mathrm{C}\right)\end{array}$ \\
\hline Me1/Em12 & TGAGTCCAAACCGGATA & GACTGCGTACGAATTGTC & UBC835 & $($ AG)8YC & 53 \\
Me1/Em15 & TGAGTCCAAACCGGATA & GACTGCGTACGAATTCTG & UBC836 & $($ AG)8YA & 53 \\
Me2/Em11 & TGAGTCCAAACCGGAGC & GACTGCGTACGAATTTCG & UBC840 & (GA)8YT & 48 \\
Me2/Em12 & TGAGTCCAAACCGGAGC & GACTGCGTACGAATTGTC & UBC841 & (GA)8YC & 54 \\
Me3/Em17 & TGAGTCCAAACCGGAAT & GACTGCGTACGAATTCCA & UBC847 & (CA)8RC & 53 \\
Me6/Em2 & TGAGTCCAAACCGGTAG & GACTGCGTACGAATTTGC & UBC873 & (GACA)4 & 54 \\
Me6/Em14 & TGAGTCCAAACCGGTAG & GACTGCGTACGAATTCAG & UBC880 & (GGAGA)3 & 54 \\
Me8/Em16 & TGAGTCCAAACCGGTGT & GACTGCGTACGAATTCGG & UBC888 & BDB $(C A) 8$ & 52 \\
Me9/Em16 & TGAGTCCAAACCGGTCA & GACTGCGTACGAATTCGG & & & \\
\hline
\end{tabular}

$\mathrm{Y}=\mathrm{G} / \mathrm{C}, \mathrm{R}=\mathrm{A} / \mathrm{G}, \mathrm{B}=\mathrm{C} / \mathrm{G} / \mathrm{T}$

5\% (ISSR) non-denaturing polyacrylamide gel and stained with $1 \%$ silver nitrate at the end of electrophoresis and photographed after the bands were clear.

Data analysis

The clear and repeated SRAP and ISSR bands were marked as " 1 " and no bands in the same position are marked as " 0 " The original matrices of 0 and 1 were generated, and total number of bands (TNB), number of polymorphic bands (NPB), percentage of polymorphic bands (PPB) were counted. The information content of each marker was calculated with the formula: PICi = 2fi (1-fi), where PICi is the polymorphic information content of marker ' $i$ ', fi is the frequency of the amplified allele, and 1-fi is the frequency of the null allele (Roldàn-Ruiz et al. 2000). Using POPGENE1.32 software (Yeh 1997), the genetic diversity indices were calculated when the pseudosettlement population was in Hardy-Weinberg equilibrium: observed allele number $(\mathrm{Na})$, effective allele number $(\mathrm{Ne})$, Nei's gene diversity $(\mathrm{H})$, Shannon information index (I), total genetic diversity $(\mathrm{Ht})$, genetic diversity within populations (Hs), genetic differentiation coefficient (Gst), and gene flow (Nm). The number of private bands ( $\mathrm{PrB})$ as well as analysis of molecular variance (AMOVA) and pairwise population differentiation (PhiPT) were calculated in GENALEX 6 (Peakall and Smouse 2006), and this software was also employed to calculate Nei's genetic identity between populations. According to the genetic similarity coefficient, the population was analyzed by unweighted pair group method using an arithmetic average (UPGMA) cluster analysis using NTSYS-pc 2.11 software (Rohlf 2000), and the cluster map was constructed. The genetic population structure of A. tsao-ko was assessed using a Bayesian model based on the combined SRAP and ISSR data in STRUCTURE version 2.3.4 (Pritchard et al. 2000). The Delta K values were used to evaluate best-fit number of population clusters using Structure Harvester V6.0 online program (Earl and Vonholdt 2012).

\section{Results}

Polymorphism analysis of SRAP and ISSR

A total of 140 bands were amplified by nine pairs of SRAP primers, of which 139 bands were polymorphic, accounting for $99.29 \%$ of the total bands. The number of bands amplified by different primers ranged from 11 (Me1/Em15 and Me8/Em16) to 21 (Me2/Em12), and the average number of bands was 15.56. A total of 175 bands were amplified by eight ISSR primers, and the number of bands amplified by each primer ranged from 12 (UBC840) to 34 (UBC836), with an average of 23.25. The percentage of polymorphic bands (PPB) was $99.46 \%$. From the polymorphic information (PIC) of the marker, it was observed that when the same electrophoretic method analyzed A. tsao-ko polymorphism, the SRAP marker revealed a slightly higher PIC value than the ISSR marker (Table 3). Our results 
show that both SRAP and ISSR were suitable to assess the genetic relationships among A. tsao-ko accessions (Fig. 2).

Genetic diversity in populations

With SRAP, the mean percentage of polymorphic bands (PPB) was $59.29 \%$, ranging from $25.71 \%$ (BS) to $77.86 \%$ (JP), whereas the mean observed number of alleles (Na), effective number of alleles (Ne), Nei's gene diversity $(\mathrm{H})$, and Shannon's information index (I) were $1.593,1.274,0.168$, and 0.262 , respectively. The JP population exhibited the highest $\mathrm{H}$ value (0.240), while the BS population had the lowest $\mathrm{H}$ (0.069) (Table 4). With ISSR, the mean PPB was $57.73 \%$, ranging from $37.10 \%$ (BS) to $69.89 \%$ (LVC), and the mean $\mathrm{Na}, \mathrm{Ne}, \mathrm{H}$, and I were $1.577,1.194$, 0.130 , and 0.214 , respectively (Table 4 ). BS population exhibited the lowest $\mathrm{H}$ value (0.095) again, but YX population had the highest $H$ value $(0.153) .10$ (SRAP) and 17 (ISSR) private bands (PrB) were found in eight $A$. tsao-ko populations. The highest number of PrB was observed in population LVC (4 for SRAP and 7 for ISSR) followed by JP ( 2 for SRAP and 4 for ISSR), while no private bands were detected for PB and YY populations. Mean genetic estimates except $\mathrm{PrB}$ (mean PPB, Na, Ne, H, and I) from SRAP were higher than those from ISSR (Table 4).

Genetic differentiations among populations

POPGENE1.32 software was used to calculate the genetic differentiation level among different populations of Amomum tsao-ko. The total genetic diversity for the species $(H t)$ was 0.215 (SRAP) and 0.158 (ISSR), while the mean heterozygosity within populations (Hs) was 0.168 (SRAP) and 0.130 (ISSR). Nearly $20 \%$ of the total genetic variation in the eight populations of $A$. tsao-ko occurred among populations $($ Gst $=0.218$ for SRAP, Gst $=0.177$ for ISSR $)$, indicating that most genetic variation in A. tsao-ko occurs within populations. The gene flow levels (Nm) between the populations based on SRAP and ISSR analyses were all greater than 1 (SRAP $=1.795$, ISSR $=2.321$, which indicates no significant genetic differentiation among populations (Table 5).

Furthermore, analysis of molecular variance (AMOVA) analysis showed that the percentage of variation within populations was $83.90 \%$ (SRAP) and $90.55 \%$ (ISSR), and the percentage of variation among populations was $16.10 \%$ (SRAP) and $9.45 \%$ (ISSR), which also indicated that genetic variation mainly exists within A. tsao-ko populations (Table 6). The pairwise PhiPT provided estimates of genetic differentiation between the populations. For SRAP, the highest differentiation $(0.384, P<0.01)$ was observed between population JP and BS and the lowest $(0.000$, $P<0.001)$ was observed between PB and LC. For ISSR, the highest differentiation $(0.269, P<0.01)$ was observed between population DH and $\mathrm{PB}$ and the lowest $(0.000, P<0.001)$ was observed between YY and YX. The eastern populations except YY (PB, JP and LVC) showed a clear genetic differentiation between western populations (BS and DH) (Table 7).
Table 3 List of total amplified bands and polymorphic bands generated by 9 SRAP and 8 ISSR primers

$T N B$, total number of bands; $N P B$, number of polymorphic bands; $P P B$, percentage of polymorphic bands; PIC, polymorphism information content

\begin{tabular}{llllllllll}
\hline Locus & TNB & NPB & PPB $(\%)$ & PIC & Locus & TNB & NPB & PPB (\%) & PIC \\
\hline Me1/Em12 & 17 & 17 & 100.00 & 0.268 & UBC835 & 27 & 27 & 100.00 & 0.275 \\
Me1/Em15 & 11 & 11 & 100.00 & 0.313 & UBC836 & 34 & 34 & 100.00 & 0.191 \\
Me2/Em11 & 19 & 19 & 100.00 & 0.263 & UBC840 & 12 & 12 & 100.00 & 0.245 \\
Me2/Em12 & 21 & 21 & 100.00 & 0.285 & UBC841 & 28 & 27 & 96.43 & 0.194 \\
Me3/Em17 & 15 & 15 & 100.00 & 0.214 & UBC847 & 18 & 18 & 100.00 & 0.299 \\
Me6/Em2 & 14 & 13 & 92.86 & 0.224 & UBC873 & 16 & 16 & 100.00 & 0.237 \\
Me6/Em14 & 20 & 20 & 100.00 & 0.232 & UBC880 & 28 & 28 & 100.00 & 0.190 \\
Me8/Em16 & 11 & 11 & 100.00 & 0.294 & UBC888 & 23 & 23 & 100.00 & 0.222 \\
Me9/Em16 & 12 & 12 & 100.00 & 0.338 & Mean & 23.25 & 23.13 & 99.46 & 0.232 \\
Mean & 15.56 & 15.44 & 99.29 & 0.270 & Total & 186 & 185 & & \\
Total & 140 & 139 & & & & & & & \\
\hline
\end{tabular}



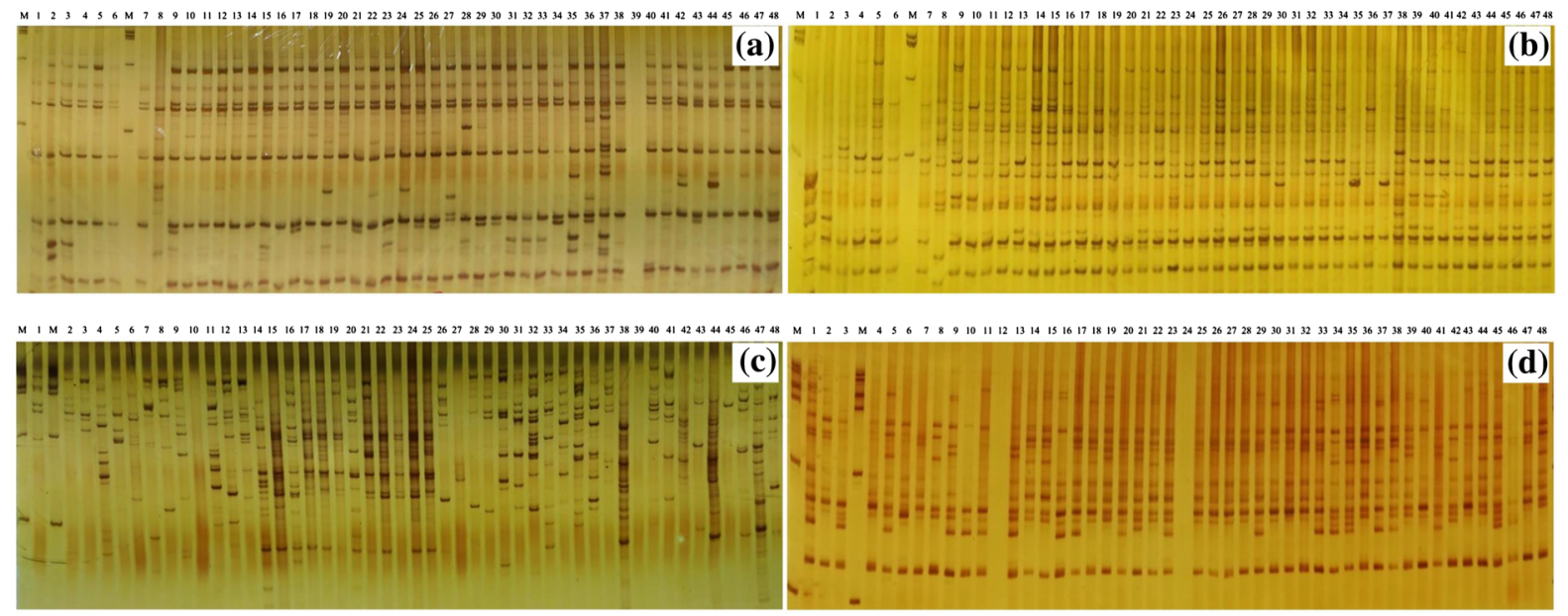

Fig. 2 Electrophoretic profiles of genomic DNA amplification products using SRAP primer Me1/Em12 (a), Me2Em12 (b) and ISSR primer UBC880 (c), UBC888 (d). Lane M indicated DNA Marker (200, 400, 700, 1000, 1500, 2000 bp). Lane 1-48 indicated partial A. tsao-ko accessions: JP8, JP48, JP55, JP59, JP64, JP84, JP91, JP103, JP108, JP109, JP118, JP119, JP128,
YY3, YY5, YY9, YY14, YY18, YY22, YY32, YY36, YY44, YY45, YY47, YY48, LVC2, LVC5, LVC12, LVC21, LVC25, LVC28, LVC34, LVC41, LVC44, LVC49, LVC50, PB1, PB2, PB19, PB21, PB30, PB31, PB41, PB45, PB48, LC1, LC2 and LC3

Table 4 Genetic diversity of A. tsao-ko populations based on SRAP and ISSR markers

\begin{tabular}{|c|c|c|c|c|c|c|c|c|c|c|c|c|}
\hline \multirow[t]{2}{*}{ Pop } & \multicolumn{2}{|l|}{ PPB } & \multicolumn{2}{|l|}{$\mathrm{Na}$} & \multicolumn{2}{|l|}{$\mathrm{Ne}$} & \multicolumn{2}{|l|}{$\mathrm{H}$} & \multicolumn{2}{|l|}{ I } & \multicolumn{2}{|l|}{ PrB } \\
\hline & SRAP $(\%)$ & ISSR (\%) & SRAP & ISSR & SRAP & ISSR & SRAP & ISSR & SRAP & ISSR & SRAP & ISSR \\
\hline PB & 70.70 & 53.23 & 1.707 & 1.532 & 1.298 & 1.189 & 0.193 & 0.130 & 0.305 & 0.213 & 0 & 0 \\
\hline JP & 77.86 & 66.60 & 1.779 & 1.667 & 1.405 & 1.180 & 0.240 & 0.130 & 0.367 & 0.222 & 2 & 4 \\
\hline YY & 41.43 & 53.76 & 1.414 & 1.538 & 1.214 & 1.191 & 0.126 & 0.125 & 0.192 & 0.203 & 0 & 0 \\
\hline LVC & 77.14 & 69.89 & 1.771 & 1.699 & 1.373 & 1.189 & 0.225 & 0.136 & 0.348 & 0.234 & 4 & 7 \\
\hline YX & 66.43 & 66.13 & 1.664 & 1.661 & 1.280 & 1.232 & 0.177 & 0.153 & 0.280 & 0.251 & 1 & 2 \\
\hline LC & 67.80 & 65.59 & 1.679 & 1.656 & 1.313 & 1.218 & 0.195 & 0.147 & 0.304 & 0.242 & 1 & 2 \\
\hline BS & 25.71 & 37.10 & 1.257 & 1.371 & 1.116 & 1.151 & 0.069 & 0.095 & 0.108 & 0.150 & 0 & 1 \\
\hline DH & 47.14 & 49.46 & 1.471 & 1.495 & 1.192 & 1.200 & 0.122 & 0.125 & 0.193 & 0.199 & 2 & 1 \\
\hline Mean & 59.29 & 57.73 & 1.593 & 1.577 & 1.274 & 1.194 & 0.168 & 0.130 & 0.262 & 0.214 & 1.25 & 2.125 \\
\hline Total & 99.29 & 99.46 & 1.993 & 1.995 & 1.342 & 1.229 & 0.217 & 0.158 & 0.348 & 0.272 & 10 & 17 \\
\hline
\end{tabular}

$P P B$, percentage of polymorphic bands; $N a$, observed number of alleles; $N e$, effective number of alleles; $H$, Nei's gene diversity; $I$, Shannon's information index; $\operatorname{Pr} B$, Private bands

Genetic identity analysis

The results of Nei's genetic identity are shown in Table 8. SRAP analysis showed that the genetic identity between the eight $A$. tsao-ko populations ranged from 0.857 (JP and BS) to 0.983 (LC and YX), with an average of 0.937 . For the ISSR analysis, the genetic identity of the eight A. tsao-ko populations ranged from 0.920 (JP and BS) to 0.991 (LC and YX), with an average of 0.963 . ISSR analysis also indicated that LC population exhibited the highest similarity with YX population, while JP and BS showed the lowest similarity. 
Table 5 Genetic differentiation coefficients of A. tsao-ko populations

\begin{tabular}{lllll}
\hline Markers & $\mathrm{Ht}$ & $\mathrm{Hs}$ & $\mathrm{Gst}$ & $\mathrm{Nm}$ \\
\hline SRAP & 0.215 & 0.168 & 0.218 & 1.795 \\
ISSR & 0.158 & 0.130 & 0.177 & 2.321
\end{tabular}

$H t$, total genetic diversity; $H s$, genetic diversity within populations; Gst, genetic differentiation coefficient; $\mathrm{Nm}$, gene flow
Cluster analysis and PCoA

The UPGMA cluster analysis based on SRAP, ISSR and SRAP + SSR data revealed genetic relationship among 91 A. tsao-ko accessions (Fig. 3). Based on the SRAP data, 91 accessions were grouped into two main clusters (Cluster I and Cluster II) (Fig. 1a) at the 0.668 similarity coefficient level. Cluster I contained 63 accessions from all of the eight A. tsao$k o$ populations, could be further grouped into two sub-

Table 6 Analysis of molecular variance (AMOVA) in A. tsao-ko populations

\begin{tabular}{|c|c|c|c|c|c|c|}
\hline Source & df & Sum of squares & Mean squares & Variation components & Percentage of variance & $P$-value \\
\hline \multicolumn{7}{|l|}{ SRAP } \\
\hline Among populations & 7 & 435.277 & 62.182 & 3.754 & $16.10 \%$ & \\
\hline Within populations & 83 & 1623.844 & 19.564 & 19.564 & $83.90 \%$ & 0.001 \\
\hline \multicolumn{7}{|l|}{$I S S R$} \\
\hline Among populations & 7 & 511.045 & 73.006 & 3.487 & $9.45 \%$ & \\
\hline Within populations & 83 & 2773.559 & 33.416 & 33.416 & $90.55 \%$ & 0.001 \\
\hline
\end{tabular}

Table 7 Pairwise population PhiPT values based on SRAP (above diagonal) and ISSR (below diagonal) between A. tsaoko populations

${ }^{*} P<0.05, * * P<0.01$

Table 8 Nei's genetic identity among eight $A$. tsao-ko populations by SRAP markers ( above diagonal) and ISSR markers ( below diagonal)

\begin{tabular}{lllllllll}
\hline & $\mathrm{PB}$ & $\mathrm{JP}$ & $\mathrm{YY}$ & $\mathrm{LVC}$ & $\mathrm{YX}$ & $\mathrm{LC}$ & $\mathrm{BS}$ & $\mathrm{DH}$ \\
\hline $\mathrm{PB}$ & - & $0.061^{*}$ & $0.161^{* *}$ & 0.026 & $0.068^{*}$ & 0.000 & $0.296^{* *}$ & $0.239 * *$ \\
$\mathrm{JP}$ & 0.050 & - & $0.261^{* *}$ & 0.028 & $0.153^{* *}$ & $0.067^{*}$ & $0.384^{* *}$ & $0.329 * *$ \\
$\mathrm{YY}$ & $0.136^{* *}$ & $0.124^{* *}$ & - & $0.218^{*}$ & $0.064^{*}$ & $0.118^{* *}$ & $0.085^{* *}$ & $0.105^{* *}$ \\
$\mathrm{LVC}$ & $0.117^{*}$ & $0.069^{*}$ & $0.085^{* *}$ & - & $0.133^{* *}$ & 0.034 & $0.357^{* *}$ & $0.296^{* *}$ \\
$\mathrm{YX}$ & $0.145^{* *}$ & $0.098^{* *}$ & 0.000 & $0.077^{* *}$ & - & 0.032 & $0.139^{* *}$ & $0.110^{* *}$ \\
$\mathrm{LC}$ & $0.094^{*}$ & $0.083^{* *}$ & 0.002 & 0.026 & 0.011 & - & $0.211^{* *}$ & $0.173^{* *}$ \\
$\mathrm{BS}$ & $0.145^{* *}$ & $0.188^{* *}$ & 0.001 & $0.129 * *$ & $0.076^{*}$ & 0.014 & - & $0.116^{* *}$ \\
$\mathrm{DH}$ & $0.268^{* *}$ & $0.217^{* *}$ & 0.032 & $0.19^{* *}$ & 0.046 & $0.067 *$ & $0.074 *$ & - \\
\hline
\end{tabular}

\begin{tabular}{lllllllll}
\hline Population & PB & JP & YY & LVC & YX & LC & BS & DH \\
\hline PB & - & 0.964 & 0.927 & 0.968 & 0.968 & 0.981 & 0.900 & 0.912 \\
JP & 0.979 & - & 0.894 & 0.975 & 0.943 & 0.963 & 0.857 & 0.870 \\
YY & 0.962 & 0.948 & - & 0.905 & 0.962 & 0.946 & 0.969 & 0.960 \\
LVC & 0.982 & 0.984 & 0.953 & - & 0.948 & 0.972 & 0.870 & 0.884 \\
YX & 0.975 & 0.965 & 0.982 & 0.972 & - & 0.983 & 0.936 & 0.950 \\
LC & 0.981 & 0.976 & 0.980 & 0.977 & 0.991 & - & 0.925 & 0.933 \\
BS & 0.940 & 0.920 & 0.979 & 0.924 & 0.968 & 0.962 & - & 0.969 \\
DH & 0.939 & 0.926 & 0.978 & 0.931 & 0.967 & 0.962 & 0.973 & - \\
\hline
\end{tabular}

clusters (IA and IIB). Sub-cluster IA consisted of 15 accessions collected from Lvchun (4), Jinping (3), 


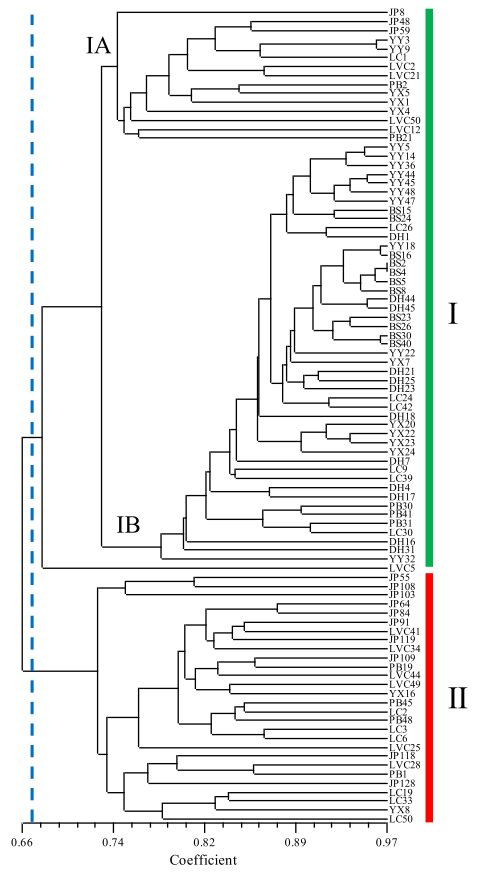

(a)

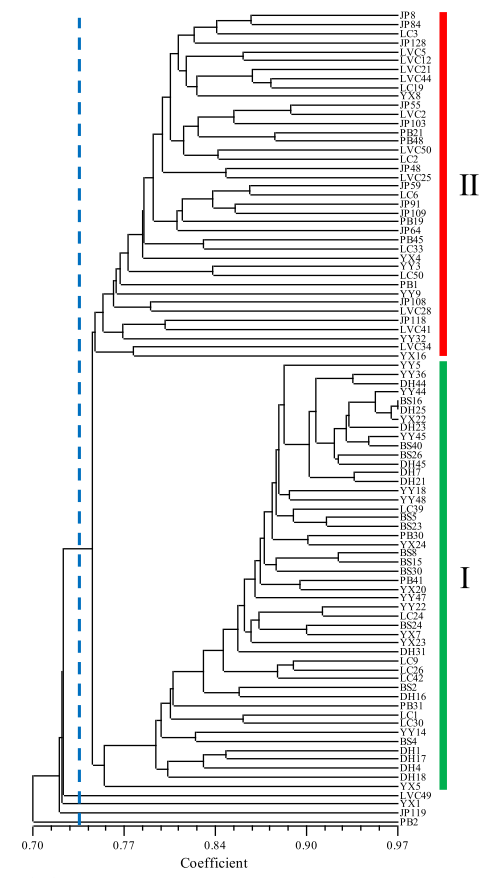

(b)

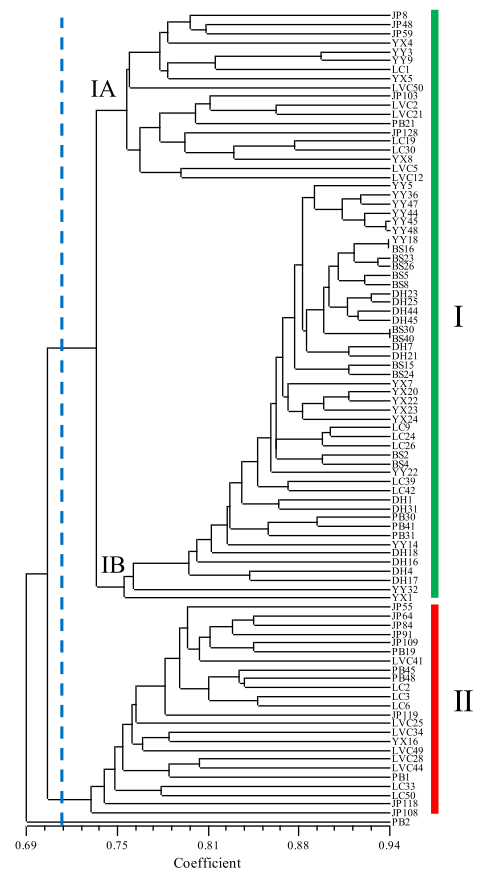

(c)

Fig. 3 UPGMA cluster of 91 A. tsao-ko accessions based on SRAP (a), ISSR (b) and combined SRAP + SSR (c) markers

Yunxian (3), Yuanyang (2), Pingbian (2), and Lancang (1); sub-cluster IB included 48 accessions collected from Dehong (12), Baoshan (11), Yuanyang (10), Lancang (6), Yunxian (5), Pingbian (3), and Lvchun (1). Cluster II comprised 28 accessions collected from Jinping (10), Lvchun (6), Lancang (6), Pingbian (4), and Yunxian (2). Based on the ISSR data, 87 accessions were successfully divided into two major clusters (with a similarity index of 0.735 ) except for LVC49, YX1, JP119 and P2 (Fig. 3b). Cluster I consisted of 48 accessions from populations Dehong (12), Baoshan (11), Yuanyang (9), Lancang (7), Yunxian (6), Pingbian (3), which was similar to subcluster IB based on the SRAP data. Unlike with SRAP analysis, 11 accessions (JP8, JP48, JP59, YY3, YY9, LVC2, LVC 12 and PB21) from Sub-cluster IA (SRAP) were grouped into Cluster II. In order to obtain more accurate genetic estimates, combined analysis was carried out using all the SRAP and ISSR data together. A dendrogram (Fig. 3c) that grouped all the accessions into two clusters. Cluster I that included 66 accessions collected from eight A. tsao-ko populations was further divided into two sub-clusters. Subcluster IA contained 19 accessions collected from Jinping (5), Yuanyang (2), Lvchun (5), Pingbian (1),
Yunxian (3), and Lancang (3); sub-cluster IB included 47 accessions collected from Yuanyang (10), Pingbian (3), Yunxian (6), Lancang (5), Baoshan (11), and Dehong (12). Cluster II included 24 accessions, 8 from Jinping, 6 from Lvchun, 4 from Pingbian, 1 from Yunxian, and 5 from Lancang. The results of principal coordinate analysis for the combined data were consistent with the UPGMA cluster analysis based SRAP + SSR markers, and all accessions were divided into two groups, I and II. The first two principal coordinates explained $25.70 \%$ of the total variation, with $\mathrm{PC} 1$ accounting for $20.22 \%$ and $\mathrm{PC} 2$ for $5.48 \%$ (Fig. 4).

\section{Structure of A. tsao-ko germplasm genotypes}

To further elucidate the relationships among the $A$. tsao-ko accessions, the population structure was analyzed using STRUCTURE software. According to Structure Harvester V6.0, the best K value was 2 . All accessions were divided into two groups (Fig. 5). Group I (green) contained 41 individuals from YY (9), LC (5), YX (5), BS (11), and DH (11), while group II (red) contained 38 germplasm resources collected from JP (12), LVC (11), PB (6), LC (6), and YX (3). 


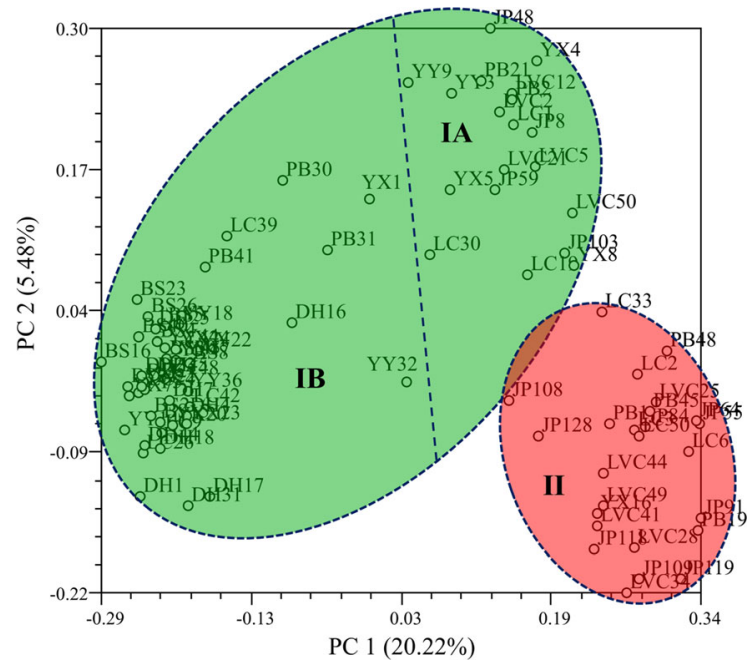

Fig. 4 Principal coordinates analysis (PCA) of the 91 A. tsao-ko accessions based on SRAP + SSR markers

\section{Discussion}

Genetic diversity evaluation within a cultivated crop is a prerequisite for plant breeding and conservation of genetic resources (Wang et al. 2012). Molecular marker technology is a robust approach to study the genetic diversity of crop germplasm resources (Liao et al. 2012). In this study, SRAP and ISSR markers were used to analyze the genetic diversity of eight cultivated populations of A. tsao-ko in southwest China. For the SRAP markers, 15.56 bands per primer set were scored, and 23.25 bands were obtained per primer set by ISSR amplification. ISSR markers generated more bands than SRAP markers. This difference may be because ISSR amplified the whole plant genome sequence, while SRAP amplified only the open reading frames (ORFs) (Li and Quiros 2001;

(a)

\begin{tabular}{ccccccc}
$\mathbf{K}$ & Reps & Mean LnP(K) & Stdev LnP(K) & $\mathbf{L n}^{\prime}(\mathbf{K})$ & $\left|\mathbf{L n} \mathbf{n}^{\prime(K)}\right|$ & Delta K \\
\hline 1 & 5 & -21002.74 & 2.052559 & - & - & - \\
2 & 5 & -17452.6 & 10.489995 & 3550.14 & 2756.16 & 262.741778 \\
3 & 5 & -16658.62 & 163.298552 & 793.98 & 446.52 & 2.734378 \\
4 & 5 & -16311.16 & 141.029227 & 347.46 & 104.24 & 0.739138 \\
5 & 5 & -15859.46 & 107.401317 & 451.7 & 134.44 & 1.251754 \\
6 & 5 & -15542.2 & 113.271687 & 317.26 & 62.86 & 0.554949 \\
7 & 5 & -15287.8 & 146.597527 & 254.4 & 133.84 & 0.912976 \\
8 & 5 & -14899.56 & 45.904063 & 388.24 & - & -
\end{tabular}

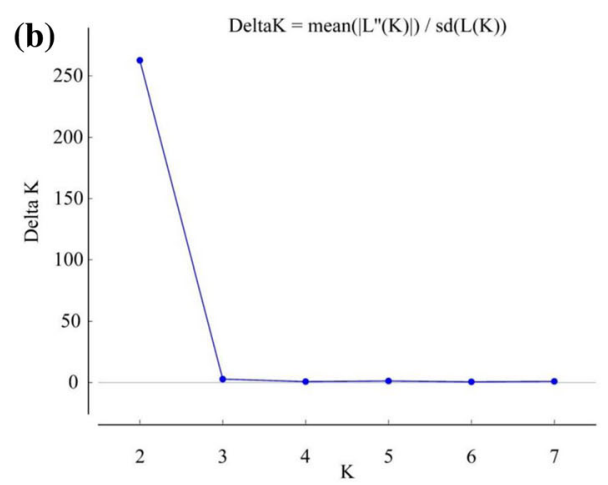

(c)

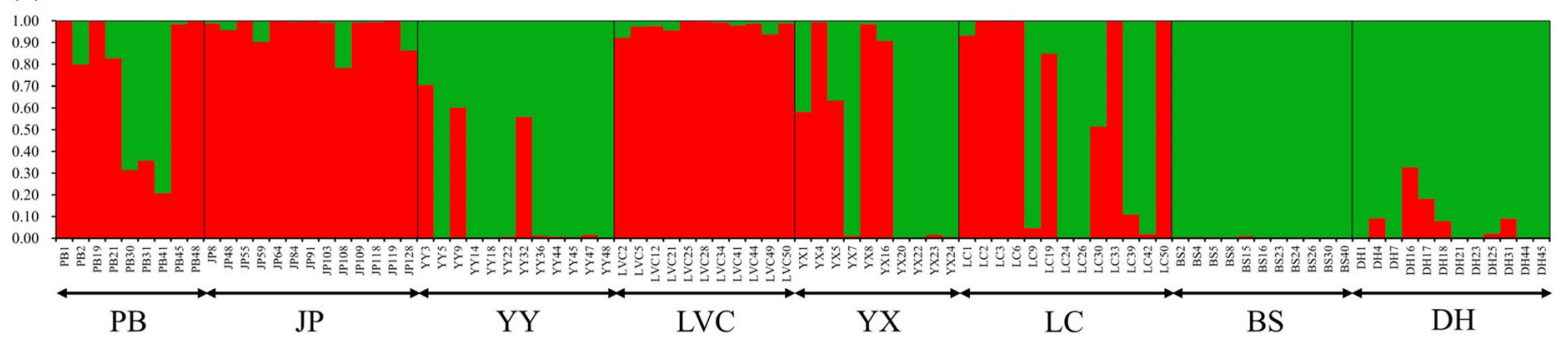

Fig. 5 Graphical representation of population structure using STRUCTURE 2.3.4 and Structure Harvester v6.0 program, a Evanno table output, $\mathbf{b}$ the median and variance of the

Accessions with admixed population assignments were from JP (1), YY (3), PB (4), LC (1), YX (2), and DH (1) populations. estimated probability value for each $\mathrm{K}$ value, c Population structure of 91 A. tsao-ko accessions

Zietkiewicz et al. 1994). SRAP and ISSR also had a higher percentage of polymorphic bands (PPB) in $A$. tsao-ko $(\mathrm{SRAP}=99.29 \%$; ISSR $=99.48 \%)$, indicating that both markers could effectively reveal the polymorphism among A. tsao-ko germplasm. The PIC revealed by SRAP $(0.270)$ was higher than that of 
ISSR (0.232), suggesting that SRAP markers are more efficient in distinguishing differences between A. tsaoko germplasms. In previous studies, there have been many reports on the combination of SRAP and ISSR markers to study plant germplasm resources, and the genetic diversity revealed by SRAP and ISSR markers was highly consistent (Liao et al. 2012; Peng et al. 2015; Wu et al. 2010; Yan et al. 2019). In our study, Mantel's test showed that SRAP and ISSR analysis results were highly and significantly correlated at the population level $(r=0.969, \mathrm{p}<0.01)$, and the combination of the two type markers can better reveal the genetic variation of $A$. tsao-ko germplasm.

$\mathrm{PPB}, \mathrm{H}$, and I are important parameters to measure the level of genetic diversity of species. Zhang and Yang (2008) counted the average level of genetic diversity parameters of 66 species of plants based on ISSR markers $($ Ppop $=0.403$, Hpop $=0.123$, Ipop $=$ 0.186). In our study, a high level of genetic diversity was observed at the population level (Ppop $=59.29 \%$, Hpop $=0.168$, Ipop $=0.262$ in SRAP; Ppop = $57.73 \%$, Hpop $=0.130$, Ipop $=0.214$ in ISSR). Plant genetic diversity can be affected by several factors including gene mutation, natural selection, genetic drift, gene flow, and plant breeding systems (Hamrick and Godt 1996; Nybom 2004). Of all these factors, the breeding system is an important factor that determined the genetic diversity in plant species. The out-breeding plant has higher genetic diversity than a self-breeding plant. A. tsao-ko is one of the flexistylous gingers with populations comprising two types of floral morphs termed cataflexistylous morphs and anaflexistylous morphs. This mechanism can promote cross-pollination where genes can be fully exchanged among individuals in the population ( $\mathrm{Li}$ et al. 2017). Private alleles present in populations are useful for conservation and utilization of plant germplasm resources (Kalinowski 2004; Lee et al. 2020). In our study, the highest number of private alleles was observed in LVC population (private bands $=11$ ), followed by JP population (private bands $=6$ ), more number of private bands indicates the presence of specific genes or sequences in both populations (Saboori et al. 2020). The JP and LVC populations showed much higher diversity parameters, and those two populations are located at the southeast of the Yunnan Province-a traditional A. tsao-ko growing region. Specifically, Jinping County, known as the hometown of A. tsao-ko, has cultivated the plant for more than 400 years (Ma et al. 2020). The quality of the A. tsao-ko is excellent, and many variation types have been retained in the long-term cultivation process. In previous studies, we used RAPD markers to analyze levels of genetic diversity in eight A. tsao-ko populations, and Ppop, Hpop, and Ipop values were 57.18\%, 0.121, and 0.202, respectively (Lu et al. 2018), indicating that the RAPD marker system is not as effective as SRAP or ISSR in detecting the diversity of A. tsao-ko.

Previous studies have shown that the genetic diversity of species dominated by self-crossing mainly exists among populations, while that of outcrossing species mainly exists within populations (Xiang et al. 2020; Zhou et al. 2020). In this study, POPGENE software analysis showed that the genetic differentiation of A. tsao-ko mainly existed within populations (Table 5), which was consistent with the result by RAPD and SSR markers (Lu et al. 2018, 2021). Gene flow $(\mathrm{Nm})$ helps to improve the level of genetic diversity of plant populations and is also an important factor affecting genetic differentiation. $\mathrm{Nm}>1$ can prevent the genetic differentiation of a population through genetic drift (Slatkin 1987). In this study, $\mathrm{Nm}=1.795$ (SRAP) and 2.321 (ISSR) among A. tsao$k o$ populations were enough to resist the genetic differentiation caused by genetic drift. AMOVA analyses also revealed that most genetic variation detected by SRAP $(83.90 \%)$ ISSR $(90.55 \%)$ resided within populations of A. tsao-ko. In order to better understand the genetic relationships between pairs of populations, pairwise PhiPT were estimated, the eastern populations ( $\mathrm{PB}, \mathrm{JP}$ and LVC) showed higher pairwise variation with western populations (BS and DH). A. tsao-ko from origin regions (Jinping County of China) gradually being introduced to other Yunnan regions ( $\mathrm{Lu}$ et al. 2018), the high genetic differentiation between different populations may be explained by founder effect, genetic drift and differences in the choice of individuals made by breeders (Hundertmark and Daele 2010; Kuwahara et al. 2014).

In general, the genetic identity between species and populations of seed plants is approximately 0.67 and 0.90 , respectively (Wang 1994). In this study, there is a high degree of genetic identity between populations (SRAP range from 0.857 to 0.983 ; ISSR range from 0.920 to 0.991 ), which is due to two factors. First, $A$. tsao-ko is mainly distributed in southwest China and north Vietnam at altitudes ranging from 1300 to $1800 \mathrm{~m}$, where it thrives in well-drained, moist, 
organic-matter-rich soil in shade or partial shade. Narrow distribution areas and special habitats lead to the high genetic similarity between A. tsao-ko populations. Second, there is frequent germplasm exchange among producers in different populations, which reduces the genetic differentiation among populations. Consistent with pairwise PhiPT analysis, lower genetic similarity between western and eastern populations have been observed. A. tsao-ko gradually spread from the origin regions to the periphery through introduction. Generally, a higher genetic similarity is expected between neighboring populations than between distant ones for species with low dispersal ability (Sromek et al. 2019; Wright 1943).

In this study, The UPGMA analysis showed slightly different clustering pattern based on SRAP and ISSR. Eight accessions (JP8, JP48, JP59, YY3, YY9, LVC2, LVC 12 and PB21) from Cluster I (Fig. 3a for SRAP) were grouped into Cluster II (Fig. 3b for ISSR), similar results were observed in other studies ( $\mathrm{Li}$ et al. 2013; Wang et al. 2012; Wu et al. 2014), this could be related to different portion of genome amplified by different marker systems (Parthiban et al. 2018). Therefore, the combination of the two markers could result in more comprehensive and accurate analysis of genetic relationships among accessions (Wu et al. 2010). UPGMA clustering and PCoA analysis based a combination of SRAP + SSR revealed similar results. All accessions were divided into two groups, the samples from different populations were interlaced with each other, indicating that the correlation between genetic similarity and geographical distance is not significant. Similar results were reported in Goat's rue (Wang et al. 2012), apricot (Li et al. 2014), and Anise (Akçali Giachino 2020). This result could imply the frequent A. tsao-ko introduction across different geographical regions in a long history of A. tsao-ko cultivation. Bayesianbased population structure analysis also categorized 91 A. tsao-ko accessions into two groups. Most of the accessions collected from BS (all accessions), DH (11 accessions) and YY (9 accessions) populations were grouped under Group I (green), while Group II (red) was mainly composed of JP (12 accessions) and LVC (11 accessions) populations, this result is consistent with pairwise PhiPT analysis. The genetic differences among A. tsao-ko populations may contribute to local adaptation and artificial selection during introduction (Lu et al. 2018).
A high level of genetic diversity is important for the long-term survival of any species. Because the distribution range of Zingiberaceae plants for both medicine and food is very narrow, this study found that the genetic diversity of A. tsao-ko in Honghe Prefecture (PB, JP, YY and LVC population) is relatively high, especially in the Jinping population and Lvchun population. This study also confirms the theory that the Jinping area of Honghe Prefecture is the origin of A. tsao-ko at the molecular level. However, at present, Jinping $A$. tsao-ko is faced with many problems, such as a high incidence of diseases and pests, unstable yield, lack of cultivation management, and difficulties in seedling breeding. According to this study's results, the A. tsao-ko germplasm resources nursery was established in Jinping County. Their germplasm resources were widely collected, and highquality germplasm screening, seedling breeding, and high-yield and high-quality cultivation techniques were also carried out.

\section{Conclusions}

A. tsao-ko is a traditional Chinese medicine, condiment, and important economic crop found in the tropical forests of southwest China. In this study, SRAP and ISSR marker systems were used for the first time to evaluate the genetic diversity of A. tsao-ko germplasm from eight populations in southwest China. The SRAP marker reveals a slightly higher PIC content than the ISSR marker. A high degree of diversity was observed at the species and population levels, and different A. tsao-ko populations showed high genetic identity. POPGENE software and AMOVA analysis showed that the genetic differentiation of A. tsao-ko mainly existed within populations. UPGMA clustering, together with PCoA and Bayesian-based population structure analysis revealed that all accessions can be divided into two main groups. This indicate genetic differentiation is gradually formed in the process of introduction and cultivation. The information obtained in this study will be helpful for the protection and utilization of A. tsao-ko germplasm in China.

Acknowledgements This research was funded by National Natural Science Foundation of China (31460380); Special Basic Cooperative Research Programs of Yunnan Provincial 
Undergraduate Universities' Association (202001BA070001181); Youth Academic Backbone Project of Honghe University (2014GG0101) and Agricultural Discipline Construction Project of Honghe University (2018ZDXK02).

\section{Declarations}

Conflict of interest The authors declare no conflict of interest.

\section{References}

Akçali Giachino RR (2020) Investigation of the genetic variation of anise (Pimpinella anisum L.) using RAPD and ISSR markers. Genet Resour Crop Evol 67:763-780

Doyle JJ, Doyle JL (1987) A rapid DNA isolation procedure from small quantity of fresh leaf material. Phytochem Bull 119:11-15

Earl D, Vonholdt BM (2012) Structure harvester: a website and program for visualizing STRUCTURE output and implementing the Evanno method. Conserv Genet Resour 4:359-361

El-tayeh N, Galal H, Soliman M, Zaki H (2020) Association of morphological, ecological, and genetic diversity of Aerva javanica populations growing in the eastern desert of Egypt. Agronomy 10:402

Hamrick JL, Godt MJW (1996) Effects of life history traits on genetic diversity in plant species. Phil T R Soc B 351:1291-1298

Hundertmark KJ, Daele LJV (2010) Founder effect and bottleneck signatures in an introduced, insular population of elk. Conserv Genet 11:139-147

Kalinowski ST (2004) Counting alleles with rarefaction: private alleles and hierarchical sampling designs. Conserv Genet 5:539-543

Kim JG, Jang H, Le TPL, Hong HR, Lee MK, Hong JT, Lee D, Hwang BY (2019) Pyranoflavanones and pyranochalcones from the fruits of Amomum tsao-ko. J Nat Prod 82:1886-1892

Kuwahara K, Suzuki R, Ito Y, Mikami T, Onodera Y (2014) An analysis of genetic differentiation and geographical variation of spinach germplasm using SSR markers. Plant Genet Resour 12:185-190

Lee KJ, Lee JR, Sebastin R, Cho GT, Hyun DY (2020) Molecular Genetic Diversity and Population Structure of Ginseng Germplasm in RDA-Genebank: Implications for Breeding and Conservation. Agronomy 10:68

Li G, Quiros CF (2001) Sequence-related amplified polymorphism (SRAP), a new marker system based on a simple PCR reaction: its application to mapping and gene tagging in Brassica. Theor Appl Genet 103:455-461

Li HY, Li ZY, Cai LY, Shi WG, Mi FG, Shi FL (2013) Analysis of genetic diversity of Ruthenia Medic (Medicago ruthenica (L.) Trautv.) in Inner Mongolia using ISSR and SSR markers. Genet Resour Crop Evol 60:1687-1694

Li M, Zhao Z, Miao X (2014) Genetic diversity and relationships of apricot cultivars in North China revealed by ISSR and SRAP markers. Sci Hortic 173:20-28

Li GD, Zhang HH, Liu XL, Qian ZG, Guan KY, Yang YW (2017) Difference of reproduction between the two morphs of Amomum tsao-ko (Zingiberaceae). Guihaia 37:1312-1321 ((in Chinese))

Liao L, Guo QS, Wang ZY, Liu L, Zhu ZB (2012) Genetic diversity analysis of Prunella vulgaris in China using ISSR and SRAP markers. Biochem Syst Ecol 45:209-217

Lim T (2013) Amomum tsao-ko. Edible medicinal and nonmedicinal plants. Springer, Netherlands, pp 813-817

Liu H, Yan QS, Zou DL, Bu XL, Zhang BJ, Ma XC, Leng AJ, Zhang HL, Li DW, Wang C (2018) Identification and bioactivity evaluation of ingredients from the fruits of Amomum tsaoko Crevost et Lemaire. Phytochem Lett 28:111-115

Liu G, Jin M, Cai C, Ma C, Chen Z, Gao L (2019) Soil microbial community structure and physicochemical properties in Amomum tsaoko-based agroforestry systems in the Gaoligong Mountains. Southwest China Sustain 11:546

Lu BY, Ma ML, Wang TT, Meng HL, Lei E, Zhang W (2018) Genetic diversity and genetic relationships of Amomum tsao-ko based on random amplified polymorphic DNA markers. Int J Agric Biol 20:2032-2038

Lu BY, Ma ML, Zhang W, Meng HL, Lei E, Wang TT, Li CY (2021) Development of 23 novel microsatellite markers of Amomum tsao-ko (Zingiberaceae) based on restriction-siteassociated DNA sequencing. Mol Biol Rep 48:1943-1949

Ma ML, Wang TT, Lei E, Meng HL, Zhang W, Zhang TT, Lu BY (2020) Genetic diversity analysis of Amomum tsao-ko in Jinping based on phenotypic traits and SSR markers. Crops 36:54-59 ((in Chinese))

Nybom H (2004) Comparison of different nuclear DNA markers for estimating intraspecific genetic diversity in plants. Mol Ecol 13:1143-1155

Parthiban S, Govindaraj P, Senthilkumar S (2018) Comparison of relative efficiency of genomic SSR and EST-SSR markers in estimating genetic diversity in sugarcane. 3 Biotech 8: 1-12

Peakall R, Smouse PE (2006) GENALEX 6: genetic analysis in Excel. Population genetic software for teaching and research. Mol Ecol Notes 6:288-295

Peng X, Ji Q, Fan S, Zhang Y, Zhang J (2015) Genetic diversity in populations of the endangered medicinal plant Tetrastigma hemsleyanum revealed by ISSR and SRAP markers: implications for conservation. Genet Resour Crop Evol 62:1069-1078

Pritchard JK, Stephens M, Donnelly P (2000) Inference of population structure using multilocus genotype data. Genetics 155:945-959

Robarts DWH, Wolfe AD (2014) Sequence-related amplified polymorphism (SRAP) markers: A potential resource for studies in plant molecular biology1. Appl Plant Sci 2:1400017

Rohlf FJ (2000) NTSYS-pc, Numerical taxonomy and multivariate analysis system, Version 2.1. Exceter software, New York

Roldàn-Ruiz I, Calsyn E, Gilliland TJ, Coll R, Van Eijk MJT, De Loose M (2000) Estimating genetic conformity between related ryegrass (Lolium) varieties. 2. AFLP Characterization Mol Breed 6:593-602

Saboori S, Noormohammadi Z, Sheidai M, Marashi SS (2020) SCoT molecular markers and genetic fingerprinting of date palm (Phoenix dactylifera L.) cultivars. Genet Resour Crop Evol 67:73-82 
Shi YN, Jin H, Yang Y, Zhang LX, Zhu XY, Li W, Ji PZ, Liu DH (2014) Herbal verification of medicinal Amomum tsaoko. Med Plant 5(16-19):24

Sim S, Tan S, Kohlenberg B, Braun N (2019) Amomum tsao-ko - Chinese Black Cardamom: Detailed Oil Composition and Comparison With Two Other Cardamom Species. Nat Prod Commun 14:1934578X1985767

Slatkin M (1987) Gene flow and the geographic structure of natural populations. Science 236:787-792

Sromek L, Forcioli D, Lasota R, Furla P, Wolowicz M (2019) Next-generation phylogeography of the cockle Cerastoderma glaucum: Highly heterogeneous genetic differentiation in a lagoon species. Ecol Evol 9:4667-4682

Wang ZR (1994) Allozyme analysis in studies of plant genetic diversity and systematics. Biodivers Sci 2:91-95

Wang Z, Wang JE, Wang XM, Gao HW, Dzyubenko NI, Chapurin V (2012) Assessment of genetic diversity in Galega officinalis L. using ISSR and SRAP markers. Genet Resour Crop Evol 59:865-873

Wright S (1943) Isolation by distance. Genetics 28:114-138

Wu Z, Raven P (2000) Flora of China. Science Press

Wu YG, Guo QS, He JC, Lin YF, Luo LJ, Liu GD (2010) Genetic diversity analysis among and within populations of Pogostemon cablin from China with ISSR and SRAP markers. Biochem Syst Ecol 38:63-72

Wu ZG, Li XX, Lin XC, Jiang W, Tao ZM, Mantri N, Fan CY, Bao XQ (2014) Genetic diversity analysis of yams (Dioscorea spp.) cultivated in China using ISSR and SRAP markers. Genet Resour Crop Evol 61:639-650

Xiang L, Li XL, Wang XS, Yang J, Lv K, Xiong ZQ, Chen FQ, Huang CM (2020) Genetic diversity and population structure of Distylium chinense revealed by ISSR and SRAP analysis in the Three Gorges Reservoir Region of the Yangtze River. China Glob Ecol Conserv 21:e00805

Yan WP, Li JL, Zheng DJ, Friedman C, Wang HF (2019) Analysis of genetic population structure and diversity in Mallotus oblongifolius using ISSR and SRAP markers. Peer j 7:e7173

Yang YW, Yang ZY, Yan MR, Qian ZG, Guan KY (2014) Isolation and characterization of microsatellite markers for Amomum tsaoko (Zingiberaceae), an economically important plant in China. Genet Mol Res 13:8220-8224
Yang Z, Hu Y, Nong P, Yang R, Zhou D (2017) Investigation of Amomum tsaoko planting area and climate factors analysis of ecological suitability of Amomum tsaoko in Yunnan. Chin J Agr Resour Reg Plann 38:178-186 ((in Chinese))

Yeh FC (1997) Population genetic analysis of codominant and dominant markers and quantitative traits. Belgian $\mathrm{J}$ Bot 129:157

Zafar-Pashanezhad M, Ehsan S, Golkar P, Shiran B (2019) Genetic variation of Eruca sativa L. genotypes revealed by agro-morphological traits and ISSR molecular markers. Ind Crops Prod 145:111992

Zhang DQ, Yang YP (2008) A statistical and comparative analysis of genetic diversity detected by different molecular markers. Acta Bot Yunnanica 30:159-167 ((in Chinese))

Zhang W, Lu BY, Meng HL, Wei X, Yang ZQ, Yang SC (2019) Phenotypic diversity analysis of the fruit of Amomum tsaoko Crevost et Lemarie, an important medicinal plant in Yunnan, China. Genet Resour Crop Evol 66:1-10

Zhang XA, Kong WP, Wang XT, Zhang J, Liu LP, Wang WX, Liu YR, Wang X, Zhang HF, Deng QX (2020) Genetic diversity analysis of 34 fig varieties (Ficus carica $\mathrm{L}$.) based on ISSR molecular marker. Genet Resour Crop Evol 67:913-921

Zhou L, He XH, Yu HX, Chen MY, Fan Y, Zhang XJ, Fang ZB, Luo C (2020) Evaluation of the genetic diversity of mango (Mangifera indica L.) seedling germplasm resources and their potential parents with start codon targeted (SCoT) markers. Genet Resour Crop Evol 67:41-58

Zietkiewicz E, Rafalski A, Labuda D (1994) Genome fingerprinting by simple sequence repeat (SSR)-anchored polymerase chain reaction amplification. Genomics 20:176-183

Zong Y, Ding ML, Jia KK, Ma ST, Ju WZ (2020) Exploring active compounds of Da-Yuan-Yin in treatment of COVID-19 based on network pharmacology and molecular docking method. Chin Tradit Herb Drugs 51:836-844 ((in Chinese))

Publisher's Note Springer Nature remains neutral with regard to jurisdictional claims in published maps and institutional affiliations. 